\title{
Aggressive systemic mastocytosis with elevated myeloblasts
}

\author{
Tatsuro Jo $^{1 *}$, Kazuhiro Noguchi ${ }^{2}$ and Kazuto Shigematsu ${ }^{3}$ \\ ${ }^{1}$ Department of Hematology, Japanese Red Cross Nagasaki Genbaku Hospital, Nagasaki 852-8511, Japan \\ ${ }^{2}$ Department of Laboratory, Japanese Red Cross Nagasaki Genbaku Hospital, Nagasaki 852-8511, Japan \\ ${ }^{3}$ Department of Pathology, Japanese Red Cross Nagasaki Genbaku Hospital, Nagasaki 852-8511, Japan
}

\section{Brief history}

A 76-year-old man with chief complaints of exertional dyspnea and anterior chest pain was admitted to our hospital. Physical examination revealed rash spread all over the body. CT revealed marked splenomegaly, moderate hepatomegaly, and diffuse ground-glass opacities in the right lung with small amount of pleural effusion. CBC showed an elevated white blood cell count of $14.7 \times 10^{9} / \mathrm{L}$, with a differential of $72 \%$ neutrophils, $12 \%$ lymphocytes, $14 \%$ monocytes, and $2 \%$ myeloblasts. Other laboratory findings included a hemoglobin level of $7.4 \mathrm{~g} / \mathrm{dL}$ and a platelet count of $9 \times 10^{6} / \mathrm{L}$. Subsequent evaluation of bone marrow (BM) aspirates revealed a hypercellular marrow with $10.8 \%$ myeloblasts and megakaryocytes at less than 7000/L; no significant dysplasia was observed, and karyotype analysis was normal. Results of pathological analyses of the BM aspirates are shown in Figure 1. Findings included a markedly hypercellular BM with multiple nodular infiltrates (panel A) comprising aggregates of atypical cells (panels B and C). These cells showed very strong positive results for CD117 (panel D) and CD25 (panel E) and were also positive for CD33 and CD68 and negative for CD15 (data not shown). Therefore, these abnormal cells were identified as mast cells. Moreover, $10-20 \%$ of these cells were CD2 and tryptase positive (panels $F$ and $G$ ). Most of the mast cells were atypical in shape with spindly, hypogranular cytoplasm, and oval or elliptical nuclei (panels B, C, and H). On the basis of these findings, the patient was diagnosed with aggressive systemic mastocytosis (SM). However, serum tryptase levels were not determined and the presence of the $K T^{\mathrm{D} 816 \mathrm{~V}}$ mutation was not evaluated.

\section{Discussion and conclusion}

SM with associated hematologic neoplasm (SM-AHN) is the second most common subtype of SM. Myelodysplastic syndrome (MDS) is diagnosed in approximately $20 \%$ of cases of SM-AHN $[1,2]$. In this patient, myeloblasts were detected at $2 \%$ and $10.8 \%$ in the peripheral blood (PB) and $\mathrm{BM}$, respectively; however, we observed no significant dysplasia and no chromosomal abnormalities. As such, we were unable to reach a diagnosis of MDS and leukemia. Therefore, the diagnosis of SM-AHN was not selected. Elevation of myeloblasts in both PB and BM may suggest the diagnosis of MDS or leukemia, which may lead to misdiagnosis and inappropriate treatment. This presentation underscores the importance of substantial pathological examination for the accurate diagnosis of aggressive SM.

\section{Conflict of interest}

The authors declare that they have no conflict of interest.
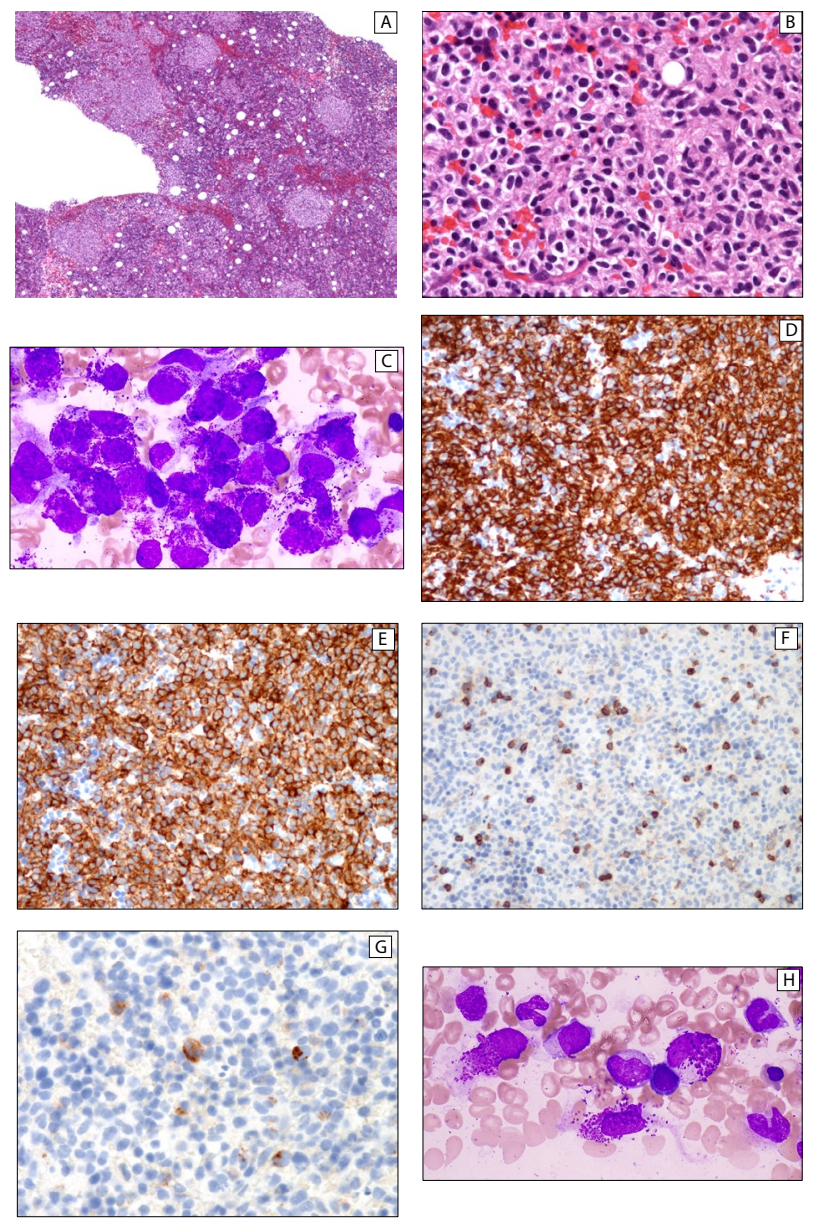

Figure 1. Morphologic features of the patient's abnormal mast cells. A. Proliferation of mast cells in a nodular pattern within the bone marrow; hematoxylin and eosin staining $(H \& E, \times 40)$. B. Mast cells with round to elliptical nuclei within bone marrow nodules $(\mathrm{H} \& \mathrm{E}, \times 400)$. C. May-Giemsa staining $(\times 1000)$. D. Immunoreactive CD117 $(\times 200)$. E. Immunoreactive CD25 $(\times 200)$. F. Immunoreactive CD2 $(\times 200)$. G. Tryptase staining $(\times 400)$. H. May-Giemsa staining $(\times 1000)$

*Correspondence to: Tatsuro Jo $\mathrm{MD}, \mathrm{PhD}$, department of Hematology, Japanese Red Cross Nagasaki Genbaku Hospital, Morimachi 3-15, Nagasaki 852-8511, Japan, Tel: +81-95-847-1511; Fax: +81-95-841-9613; E-mail: firetj@nagasaki-med.jrc.or.jp

Key words: aggressive systemic mastocytosis, myelodysplastic syndrome

Received: February 02, 2020; Accepted: February 15, 2020; Published: February 19,2020 


\section{References}

1. Lim KH, Tefferi A, Lasho TL, Finke C, Patnaik M, et al. (2009) Systemic mastocytosis in 342 consecutive adults: Survival and prognostic factors. Blood 113: 5727.
2. Pardanani A, Lim KH, Lasho TL, Finke C, McClure RF, et al. (2009) Prognostically relevant breakdown of 123 patients with systemic mastocytosis associated with other myeloid malignancies. Blood 114: 3769.

Copyright: (C2020 Jo T. This is an open-access article distributed under the terms of the Creative Commons Attribution License, which permits unrestricted use, distribution, and reproduction in any medium, provided the original author and source are credited. 